\title{
Historia de la filosofía y formación filosófica
}

\author{
José Ignacio Palencia
}

$\mathbf{E}$

1 título de lo que quiero exponer: "Historia de la filosofía y formación filosófica", incluye de propósito una ambigüedad en la palabra formación; quizás incluya otras, no de palabras sino de conceptos, pero a esas hemos de atender después; por lo pronto trataremos de aclarar qué se entiende aquí por formación.

Una tradición humanística ilustrada, heredera de los medievales e incluso de Platón, ve la formación como un proceso en el sujeto y supondría, de la expresión "formación filosófica" significados o connotaciones iales como los de que un sujeto-alumno se forma en la filosofia, en la humanidad, en las humanidades, o en su ser humano - si se quiere, en la cultura - por la filosofia; filosofía que es adjetivo e instrumento de un intento sustantivo, formación.

Organones aristotélicos o baconianos, discursos del método, medicinas o reglas del entendimiento y aun críticas de la razón, mucho deben como intentos a esta tradición; por no hablar de diálogos ciceronianos o platónicos, venationes o cacerías de la sabiduría con Nicolás de Cusa, teatros del mundo, espectáculos de la naturaleza, artes del ingenio, disciplinas de la mente, y otros entretenimientos semejantes cuya producción se extiende hasta los siglos ilustrados.

De aquí el carácter propedéutico de la filosofia — con la gramática-, en las facultades medievales y en las coloniales-novohispanas ${ }^{1}$. Carácter

Nota sobre las referencias y citas: por tratarse en la mayoría de los casos de bibliografia citada de obras conocidas y de las que existen ediciones varias, ha parecido más útil, en la mayoría de los casos, señalar la referencia a capítulos o partes que a páginas de una edición determinada. No es el caso éste, sin embargo, de la obra de Hegel, Fenomenología del Espiritu, que en sus sucesivas reimpresiones ha conservado la paginación original. Este carácter propedéutico de la Facultad de Artes o Filosofía, llegó a acentuarse a un grado tal que la mayoria de los cursantes no obtenían ni pretendían en ella sino el 
que ha de prolongarse, precisamente con las pretensiones de ser factor de formación o ilustración, hasta los colegios, academias y universidades del Renacimiento y de la Ilustración, ya avanzada la modernidad.

Hegel mismo es tributario de esta tradición y de este intento al exponer lo que sería el problema de "la formación del individuo" en la segunda parte de su prólogo a la Fenomenología, texto al que hemos de volver. ${ }^{2}$

Esta visión tradicional nos habla de la, o de las, filosofias, herencia o patrimonio de la humanidad, por cuyo conocimiento, contacto - pudiera ser contagio-, o ejercicio, "el hombre se hace humano" o "más humano" - "ontológicamente se hace hombre". ${ }^{3}$

Como método o como doctrina, la filosofía, para esta tradición, es sabiduría, y todavía escuchamos expresiones acerca de esta filía por la sofia, sea sofía el primer amor o el reposo de la senectud.

Pero esto hace ya dudar de qué sofía se trata, de la primera o de la última, de la divina o de la humana, o quizá de todas ellas y aun de algunas más que incluso no padezcan o merezcan que se les estime por legítimas sofias ya que carecen de o perturban la areté.

Bachillerato. De aquí que con los cursos de gramática y retórica que no constituían propiamente una facultad, se designara a la de artes, o a las humanidades en conjunto, como "facultades menores", en oposición a las mayores (Teologia, Derecho y Medicina). Respecto a la gramática y retórica los cursos de artes se correspondían como la enseñanza media superior se corresponde a lo que es hoy la escuela secundaria.

La obtención de grados como los de licenciado y doctor en Filosofía no era imposible, pero no era usual y suponía otros ejercicios académicos más que un currículo a seguir. De entre estos ejercicios formaba parte no menor la dedicación a la docencia como "repetidor" - especie de ayudante o repasante- de los cursos de un maestro principal y ya graduado. Sin embargo y dado que las cátedras que requerian de grados para su ejercicio se otorgaban por oposición, las más de las veces aspiraban a ellas licenciados o doctores de otras facultades, sobre todo Medicina y Teologia, o aun de Derecho, que eran los docentes más comunes en la Facultad de Arte. Más todavía, si la explicación o comentario directo de los textos filosóficos, por ejemplo de Aristóteles, Tomás de Aquino o Suárez, aunque infrecuente, tenía su propio sitio en los cursos de la Facultad de Artes, como ejercicio incluso para los repetidores o pasantes de otras facultades, la discusión normal y exposición de las cuestiones especulativas, no sólo metafisicas, más avanzada o más profunda que los cursos generales de bachillerato, quedaba cometida, como ejercicio de enseñanza, a los doctores y a los cursos de la Facultad de Teología, así como acaecía con los avances de la física respecto a la Facultad de Medicina.

Esta división y usos, vigentes en la Nueva Espana por lo menos hasta la expulsión de los jesuitas y la supresión de sus colegios y la fundación de instituciones nuevas e ilustradas en tiempos de Carlos III, se refleja todavia muy clara en el texto de Kant sobre El Conflicto de las Facultades, del que hay edición en español (Losada, Buenos Aires, sin fecha).

G.W.F. Hegel, Fenomenología del Espiritu. Trad. W. Roces y R. Guerra. FCE, México, primera edición en español, 1966. Prólogo, II, 3, p. 21.

Para su correcta comprensión, este texto ha de leerse en relación al que aparece en el mismo prólogo, I, 2; p. 9, 'la formación del presente', del que hemos derivado el uso del término "formación cultural", e incluso "formación filosófica", no en su senticlo o 
Son, pues, tantas las sofías auténticas, sedicentes o supuestas, que, parece, se impone una elección entre ellas; y, si hay primeras y últimas o una última que pasa por primera y otros personajes semejantes como en las comedias de equivocaciones, ya no "la recta razón" sino los individuos existentes en cuya formación se hacen presentes, nos sentimos convocados a enjuiciarlas y determinarlas u ordenarlas y, llamándolas a juicio, desnudarlas y probar sus cualidades: si es que son o no auténticas sofias que merezcan ser amadas:

habiendo aprendido... que no se podría imaginar nada tan extraño y poco creíble que no haya sido dicho por algún filósofo... (el filósofo se resuelve a) fingir que nada de lo que hasta entonces había entrado en (su) mente era más verdadero que las ilusiones de (los) sueños. ${ }^{4}$

Pero cuando Descartes estudió en el Colegio de La Fleche, no existían cursos de historia de las Doctrinas Filosóficas; ni menos aún la pretensión de que esos u otros semejantes de Historia de la Filosofía pudiesen constituir la Introducción, menos todavía la Formación, en la Filosofía. Monsieur Descartes sin embargo constituye un referente necesario no sólo para quienes profesionalmente se dedicarán a la filosofía, sino para la ciencia de que nos valemos y la cultura en que hoy vivimos, pues independientemente de nuestras personales posiciones respecto del cartesianismo, reconocemos en su método y en sus doctrinas -que no pocas nos resultan peregrinas opiniones-, la expresión o el exponente, como

carácter activo - como en 'la formación del individuo'-, sino contrapuesto a éste, con un sentido que se suele decir objetivo, cosificado o como 'muerta objetividad' —en términos del propio Hegel-, diríamos nosotros.

Este sentido "humanístico" de la filosofia y su estudio, vinculado al griego de paideia (Cf. Aulo Gelio, Noctes Atticae xn, 16), se encuentra, por ejemplo muy presente en Cicerón (p.e. De Senectute, De Natura Deorum, De Republica, et pass.). La importancia de esta presencia nos remite a la consideración del enorme peso específico que la tradición de estudios 'humanísticos' concediera al propio Cicerón como modelo de 'filosofar' en el ámbito de los 'Colegios' de enseñanza media, no sólo en los regidos por jesuitas ni sólo en Nueva España, pero ciertamente en ellos -y en el caso de nuestra tradición, a partir de éstos-. La comprensión de ese momento y del peso específico otorgado a la 'filosofía de Cicerón' en esa Formación, nos permite comprender mejor las partes autobiográficas que dedica Descartes a su propia Formación - con los jesuitas de La Fleche-, en sú Discurso del Método, asi como el significado y el alcance de las sucesivas reformas en los estudios de filosofía, entre nosotros intentadas - de los jesuitas del Siglo xvill a Dosé María Luis Mora-, e inclusive hasta Barreda, aunque éste enfrentado de algún modo a dicha tradición.

Descartes René; Discurso del método, partes ul y iv. 
parteaguas, no sólo de las formas de manifestarse el amor o la filía por la sofia, sino de las formas de relacionarse los hombres entre sí y, también, respecto al mundo en cuanto lo transforman y se apropian de él.

Su discurso, pues - y en este caso sin mayúscula-, es para nosotros ya un modo de pensamiento otro, totalmente distinto, del que pudo ser el de Aristóteles o el de Tomás de Aquino, aunque uno y otro sigan hablando de la Verdad, de la sustancia o lo que permanece, de las causas y aun de Dios o lo divino bien que muy distinto viene a ser lo que cada uno de los tres designa por divino o como Dios.

Verdad o libertad, bondad, maldad... son pensadas de distinto modo por distintos hombres y en distintos tiempos, ¿por qué son distintas en distintos tiempos la verdad, la libertad, etcétera?... ¿por qué son distintos esos hombres que las piensan, o por qué es distinto el pensamiento?, pero, entonces, dónde queda la pregunta o la preocupación por lo que permanece ya que al menos permanece la memoria de esa sucesión de tiempos y de hombres y de pensamientos que nos hace desconfiar, a priori y por instinto de supervivencia o de conservación, ante cualquier sofía presunta que se nos presente, así venga adornada de innegables, convincentes, atractivos.

Mal comienzo, introducción o fomación, resulta pues, respecto a la sofia, una historia del amor por ella -la filosofía, que es historia de sus veleidades:
Ahora bien, cuando semejante modo de proceder preten- de ser algo más que el inicio del conocimiento, cuando tra- ta de hacerse valer como el conocimiento real, se le debe incluir, de hecho, entre las invenciones a que se recurre para eludir la cosa misma y combinar la apariencia del esfuerzo y de la seriedad con la renuncia efectiva a ellos. ${ }^{5}$

Invenciones y apariencias han formado de este modo un expediente que se expone como historia de filosofía o de la filosofia, en la que "lo verdadero es, de este modo, el delirio báquico, en el que ningún miembro escapa a la embriaguez, y como cada miembro al disociarse, se disuelve inmediatamente por ello mismo, este delirio es, al mismo tiempo, la quietud translúcida y simple". 6

s G.W.F. Hegel; Fenomenología del Espiritu; "Prólogo" I, 1; 'La verdad como sistema cientifico'. op cit. p. 8.

"G.W.F. Hegel; op. cit. "Prólogo", III, 3; "El conocimiento conceptual", p. 32 y Cf. p. 36 para la comprensión de lo aludido en el siguiente párrafo como entendimiento esquemático'. 
El entendimiento esquemático, entendimiento formal, cartesiano, se encuentra perdido en esta bacanal, si no aquelarre, de personajes doctrinarios y doctrinas personificadas: del amor a la sabiduría como búsqueda por la verdad de lo que permanece - del fundamento de la realidad, del conocimiento o del comportamiento-, cae, "entregado en brazos del demonio", 7 como Fausto, al infierno del escepticismo, o se enamora cual Narciso del reflejo de su propia imagen mientras vive bucólicamente la ficción arcádica de que se encuentra pastoreando al ser. ${ }^{8}$ - Y las ficciones de La Arcadia siempre atraen a Sancho Panza-

No sólo la historia de la filosofía, sino incluso los filósofos y la filosofía parecerían quizá, y ante esto - para las buenas conciencias y las almas bellas ${ }^{9}$ merecedores del destino que el filósofo Platón depara a los historiadores y poetas: se les expulsará de la República -y por supuesto de la república de los amantes del saber-, como a especuladores, fabulistas o fabuladores, "emisarios del pasado", "Tezcatlipocas agoreros de calamidades, Zaratustras de la destrucción", "que están en contra de todo y a favor de nada" dedicados a "sembrar el desorden, la confusión y el encono para impedir la atención y la solución de los problemas". ${ }^{10}$

Triste historia pues la de la filosofia como teoría - o theoría-, que de la búsqueda del ser y los principios, cae en el delirio y la embriaguez,

G.W.F. Hegel; Op. cit.CV, B, a "El placer y la necesidad", p. 214, cita modificada del Fausto de J.W. Goethe. El carácter faústico, no sólo pecaminoso sino transgresor, de la filosofía como momento de la Reflexión que se vuelve a la experiencia de la vida es, sin duda, como actuación de la négatividad frente a lo dado, una constante en la Fenomenología, de tomarla en serio y de profundizar en ella con sus implicaciones y hasta sus consecuencias -muchas explícitas en la propia obra de Hegel como aquella a que se alude en este párrafo hablando de la bacanal (Cf. op. cit. cap. VII, B, b) - , mucho avanzariamos hacia la superación de los prejuicios comúnmente divulgados sobre el pensamiento y la obra de este autor.

${ }^{8}$ A pesar de lo que el propio Heidegger, desde su narcisismo, afirma, sobre este ser (él y con él todos) "el pastor del ser". Cf. "La sentencia de Anaximandro", en Sendas Perdidas; la invocación de esta ficción tiene para nosotros mucho más de quijotesca que sentido de la realidad. Cf. Miguel de Cervantes, El Ingenioso Hidalgo D. Quijote de la Mancha, segunda parte, caps. 58,59 y 67.

9 Para estos términos, CF. G.W.F. Hegel; Fenomenología del Espiritu, C VI, C "El espíritu cieno de sí mismo, la moralidad", C 'la buena conciencia, el alma bella, el mal y su perdón que constituyen una de sus más explicitas críticas a la ética kantiana y a la moralidad burguesa, op. cit. pp. 368 y ss.

${ }^{10}$ Estas expresiones - entrecomilladas por textuales-, y otras semejantes correspondientes al discurso político, se toman como representativas, en su positividad, de un sistema -muerta objetividad para Hegel一, que las invoca y constituye en su lenguaje frente a la negatividad radical que frente a un ethos representa la filosofia o la critica. Pueden encontrarse, si se quiere, en los Discursos Políticos e Informes de Gobierno de Gustavo Díaz Ordaz, Luis Echeverría Alvarez y José López Portillo, respectivamente. 
en los pecados del escepticismo y narcisismo, hasta encontrarse involucrada -lejos de las inmutabilidades como la verdad o la bondad o la belleza-, en las cotidianidades de la cosa pública y en las calamidades de la pólis que, en defensa de su ethos juzga y condena a los filósofos como culpables de impiedad o de herejía, ${ }^{\text {"1 }}$ si no es que de disolución social.

Triste historia ésta de quienes contemplan cielos hasta caer en pozos y a quienes se ridiculiza cual "pontífices de cosas vacuas", sea que "busquen mantener el módulo fijado por los mayores en el uso de la lengua" o "vivir con nuevas normas y tratar de cosas ingeniosas y poder hacer a un lado leyes prefijadas", o se empeñen en discursos o razonamientos "para admitir o negar el discurso irresistible... sucumbiendo a la palabrería" ${ }^{12}$

La historia de un amor que alcanza a la tragedia se disuelve de este modo en la ironía de la comedia. Pero "todo esto ha sucedido en los dominios del pensamiento puro". 13 "Para la mayoría de los hombres... estas representaciones teóricas no existen"14. "Hablan del Hombre en lugar de hablar de los hombres históricos reales"15 que son tanto objetos - sensibles cuanto actividad sensible - y en cuya historia, que es una acción material, empíricamente demostrable, "las ideas dominantes son en cada época las ideas de la clase dominante... que controla los medios de producción material (y) controla también los medios de producción intelectual". ${ }^{16}$

Relaciones materiales dominantes, pues, concebidas como ideas. Relaciones de los individuos entre ellos y con la naturaleza o a partir de ella, que son excluidas de esta historia y separadas de la vida corriente como algo supraterrestre, "fijación de la actividad social, de nuestro propio producto, que se convierte en una fuerza objetiva que nos domina, que huye de nuestro control". ${ }^{17}$

Nuestra comprensión de la filosofía en su historia no puede ser la misma si nos percatamos de que aquella "concepción que no ha podido ver en la historia otra cosa ...que toda variedad de pugnas teóricas", ${ }^{18}$ no ha tomado en cuenta sino las ideas puras y ha dejado a un lado o considerado sólo un accesorio a la base real, los intereses reales, que se

"Cf. Platón, "Apología de Sócrates", en Diálogos.

12 Todos los entrecomillados de este párrafocorresponden al texto de Aristófanes, Las Nubes.

${ }^{13}$ C. Marx y F. Engels, La Ideologia Alemana, Introducción, A 2 "sobre la producción de la conciencia".

14 ibid.

15 ibid.

16 ibid.

17 Op. cit. loc. cit. Introducción, A 1 "Historia".

18 Op. cit. loc. cit. Introducción, A 2. 
encuentran encubiertos, sublimados o mistificados en esa objetivad pura e ideal que parece dominarnos y pretende uniformarnos al conjuro de palabras - 0 de pensamientos- sustanciales, capitales, absolutos, trascendentes, que se ofrecen como objetos - ; esto es, dados y opuestos o enfrentados-, al desinterés de la contemplación o de la reflexión sin poner de manifiesto que no son sino productos de un proceso que, si se inicia en el esfuerzo por satisfacer necesidades reales, desemboca en el mercantilismo de crear necesidades para aquello que produce, ${ }^{19}$ así sean, estas necesidades, re-putadas como o por desinteresadas, altruistas o ilustradas.

Aquella formación de que se hablara antes, resulta ahora, y de este modo, uniformación, alineamiento, adoctrinamiento y condicionamiento, no sólo de quien cree buscar el amor de la sabiduría, sino de quien sufre el dominio del saber, cuando el saber sirve al poder ${ }^{20} \mathrm{o}$ aspira a protagonizar él mismo la toma del poder —así sea el poder detrás del trono de monarcas que se dicen ilustrados o de jerarcas que se apañan, tras teorías del ser, de los valores, del hombre o de la libertad que se sustentan como ideologías y se mantienen o alimentan como agentes o instrumentos de dominación. ${ }^{21}$

El fracaso en hacer de un rey, filósofo, y el de los filósofos cuando han llegado a regir algo, parece acreditado por la propia experiencia de Platón y de quienes comparten sus creencias. Nos desviaría, además, $\cdots r$ el momento, analizarlo. El interés de los políticos en la filosofía, y la afirmación por parte de ellos de que ésta sirve al interés de la república se encuentra acreditado ya por Cicerón: ${ }^{22}$ no pues que sea movido del desinterés, sino interesados en la cosa pública y en la política, es que los hombres buscan formación, ¿será aquí adiestramiento, habilidad o cosa semejante?, en la filosofía o respecto a la filosofía.

Si comenzaron a filosofar "movidos por la admiración", ${ }^{23}$ no es ya "el cielo estrellado que está sobre mí y la ley moral que hay en mí" el motivo o el objeto de esa admiración o pasmo, sino, mucho más cer-

19) Cf. Hegel, G.W.F., Fenomenologia del Espíritu, cap. vi, B, ii, a 2 Gamma: "La utilidad como concepto fundamental de la ilustración", p. 330.

${ }^{20}$ Cf. op. cit. cap.. VI, B, i, a 1 Beta "...la conciencia noble y la conciencia vil", p. 294, y en relación a ello todo el a 2 (p. 299) "El lenguaje como la realidad del extrañamiento y de la cultura", particularmente 'el halago'

${ }^{21}$ Cf. Luis Villoro; "Filosofía y Dominación", Discurso de ingreso al Colegio Nacional, en Nexos, año 1, núm. 12, diciembre de 1978.

${ }^{22}$ Cf. vgr. M. T. Cicerón; De Natura Deorum, Lib I, cap. iv.

${ }^{23}$ Aristóteles, Metafísica, I, ij; (982 b 12).

${ }^{24}$ E. Kant, Crítica de la Razón Práctica, "Conclusión". 
canamente, la legalidad del mundo como objeto producido en el proceso por el que se constituyen tanto un objeto para un sujeto como un sujeto para un objeto.

La espontaneidad de la vida en el proceso de su desarrollo y el impulso del deseo que la mantiene permite su reproducción, ${ }^{25}$ en cuanto se distingue de lo otro como mundo natural y es de hecho ya conciencia, -así sea elemental一, supera o media el inmediato consumir para la subsistencia y entra en la dialéctica de apropiación del mundo que es, de este modo, objetivado, constituido y transformado como mundo humano - naturaleza humanizada-; uno de los sentidos que hemos de aceptar que tiene la expresión Espiritu en los textos hegelianos:

el movimiento (que) es, de este modo, el doble proceso y devenir del todo, consistente en que cada uno pone al mismo tiempo lo otro, por lo que cada uno tiene en sí los dos... juntos los dos forman el todo, al disolverse ellos mismos para convertirse en sus momentos. ${ }^{26}$

Sin embargo, en este proceso de objetivación por el que el mundo se humaniza, el espiritu se extrana de su objetividad y de su dinamismo originarios: no se reconoce en el producto de su obrar, se afirma en una subjetividad extraña o anterior al mundo, y ve en éste como objeto, sólo su carácter positivo: la condición de la cultura como formación ${ }^{27}$ se vuelve contra él como una cosa muerta, extraña, abstracta y esencial.

La formación cultural $-\mathrm{y}$ en su caso la formación filosófica como producto y exponente histórico de esa cultura en cuanto la conciencia, por la filosofía, se distancia de la inmediatez para apropiarse de su relación con su producto o para situarse con respecto a un mundo que ve ahora como ajeno, otro y en el que no se reconoce-, es así lo más opuesto y más

${ }^{25}$ Traducimos como "impulso del deseo" Begierde, utilizado por Hegel en la Fenomenología del Espiritu, y que Roces traduce "apetencia", ( tgr. Cap. IV, 3; p. 111) "El yo y la apetencia". El rico sentido del término alemán y' del concepto Hegeliano como dinamismo e impulso de la vida, pudiera incluso traducirse por 'concupiscencia' si esta palabra no tuviese en el uso connotaciones morales de indole peyorativa. Indudablemente, la apetencia o concupiscencia, impulso del deseo, llega y lleva hasta la transgresión, pero esta transgresión, como actuación de la negatividad frente al carácter positivo - muerta objerividad- de la norma o formas culturales, de los cánones, no es algo susceptible de significarse con un término peyorativo pues, frente a la pasividad del alma bella, recupera la posibilidad de ser sí mismo, y es condición de esta posibilidad ( $C f$. Hegel, Fenomenologia... cap. VI, C, c; "La buena conciencia, el alma bella, el mal y su perdón".

26. G.W.F. Hegel; Fenomenología del Espírith, "prólogo", III, 2, p. 29.

27 Op. cit. Prólogo II, 3, p. 21 "La formación del individuo" et cfr. supra nota 2. 
distante a la vida del espíritu y a las posibilidades de su desarrollo: lo verdadero y lo falso, lo bueno y lo malo, los imperativos o valores, las instituciones o las opiniones, aparecen ahora como absolutos frente a la conciencia y la limitan en las posibilidades y en el dinamismo de su esencia como vida, como impulso erótico y orgiástico, que encuentra de este modo en esta formación - de la cultura o de la filosofia-, no ya su mediación sino su mediatización.

De esta manera, lo que era herencia y se ofrecía como riqueza se convierte en lastre, lo que aparece como cauce se reconoce como cárcel: su subsistencia como lo que permanece o lo inmutable frente a lo cambiante y contingente, ya no sustenta o fundamenta sino asfixia y aniquila.

Las ideas funcionan como ideología "han tomado (adquirido), una especie de forma objetiva"28 fuera del control de los individuos realmente existentes, "de quienes se han separado y a quienes se enfrentan...", 29 "hecho por el cual ellos quedan despojados del contenido real de su vida [y] convertidos en individuos abstractos". ${ }^{30}$

Frente a esta formación filosófica como formación cultural con su racionalidad que le es propia -inmanente, inherente-, no se trata, por supuesto, de asumir la formación filosófica como formación del individuo, sólo como un proceso de desarrollo de o en la conciencia, —en abstracción de las condiciones reales en que se produce- ${ }^{31}$ así sea como "ciencia de la experiencia de la conciencia" ${ }^{32}$ si esta conciencia es contemplada o postulada como pura o con aspiraciones de pureza, ${ }^{33} \mathrm{como}$ natural, originaria

${ }^{28}$ C. Marx y F. Engels, La Ideologia Alemana, Introducción B, 3. El texto citado se refiere directamente a la enajenación de las fuerzas productivas de los individuos en la propiedad privada, pero esta enajenación del dinamismo activo y la capacidad transformadora del sujeto, o de su carácter constructivo respecto del objeto, es también uno de los aspectos de las formaciones culturales cuando operan como ideología alienada y alienante. Este carácter, en fin, no está desvinculado en su función de aquella otra enajenación a la que se refiere el texto.

29 Ibid.

:10) Ibid.

31 Op. cit. Introducción B 3. "Instrumentos de Producción y formas de propiedad...

32 Hegel utiliza esta frase como epígrafe o título general anterior al desarrollo de la obra, después del Prólogo en Fenomenologia del espiritu. Tomar 'experiencia' y 'conciencia' en un sentido común y no en el propio de Hegel llevaría a desvirtuar o desviar el rico y complejo sentido de esta frase como cifra de un texto que no contempla la posibilidad de la experiencia o la conciencia abstractamente, como aisladas, sino en relación al proceso en el que se producen y a las condiciones a partir de las que se producen.

33 Cf. G.W.F., Hegel; Fenomenología del espíritu, cap.. vi, C, c; "La buena conciencia, el alma bella, el mal y su perdón" en clonde ha de verse no sólo la crítica al moralismo de la ética kantiana, sino a las pretensiones esencialistas o naturalistas de cualquier ontologia 
u ontológica, y no como "un producto (de la vida misma en relación al mundo y) de las relaciones anteriores de los individuos entre ellos". ${ }^{34}$

Se trata precisamente de superar la oposición entre ambas formaciones como sustantivas -en cuanto pretenden ser autónomas u originarias-, el individuo o la filosofía - reduciendo por una parte toda esta parafernalia a su "forma material de la que depende toda esta forma intelectual"35 "que se ha convertido en autónoma frente a los individuos"36, pero abriendo por otra parte y a su vez, la reflexión —o "La Reflexión sobre la Reflexión", ${ }^{37}$ al lado activo, práctico —en este sentido, subjetivo, pero como actividad real- del que depende este producto de la reflexión como un objeto práctica y socialmente producido.

Si hasta ahora la historia de la filosofia aparece para nosotros en su sentido ambiguo como formación, no puede mantenerse como vía de formación en la filosofia mientras permanezca o se mantenga en el nivel abstracto de ser exposición - sino museo, archivo o almacén-, del pensamiento o de los pensamientos acerca de todo lo que puede ser sabido y ser tratado,

sustancialista que se pretenda en abstracción de la Historia o la Dialéctica, de lo concreto material en relación al tiempo.

${ }^{34}$ C. Marx y F. Engels, La ldeología alemana, Introducción, B 3.

35 Ibid.

36 Ibid.

${ }^{37}$ Esta expresión que bien pudiera ser de Hegel - aunque literalmente no se encuentre por lo menos en la Fenomenologia - recoge y resume a mi ver lo que es para Hegel la Filosofia: desde el epigráfico "Ciencia de la experiencia de la conciencia" hasta el casi conclusivo "saber del obrar del sí mismo" (el concepto), o la "enajenación que se enajena en ella misma" (Fenomenologia... pp. 49, 466, 473). La ambigüedad del término reflexión, por otra parte, utilizado en sus dos sentidos principales -activo y sustantivo-, en múltiples pasajes de la Fenomenologia, pone de manifiesto ya de entrada el rechazo por esta concepción de la filosofia de los límites estrechos de un sustancialismo univocista respecto a los conceptos y la superación dialéctica de las limitaciones de cualquier realismo ingenuo.

La referencia de la expresión a las múltiples formas en que aparece lo apuntado en ella en la Fenomenología, tiene la ventaja de remitimos a la experiencia y a la práctica de la Filosofía más que a una pretendidamente pura teoría de la Filosofia; de esta manera, ya desde el "Prólogo" —que es, éste sí, una teoria de la Filosofía-, y mucho más en el desarrollo de la obra del que el "Prólogo" es ya un resultado, expresiones equivalentes a la nuestra, aunque con matices que las enriquecen paso a paso - y enriquecen nuestra comprensión-, se podrían hacer notar por citar sólo unas cuantas:

"...esta rectificación de su opinión obliga al saber a volver de nuevo sobre la proposición y a captarla ahora de otro modo". (Prólogo, p. 42); "proceso que se engendra a sí mismo, que se desarrolla y retorna a sí". Jbid. p. 43; "conciencia de lo que es para ella lo verdadero y conciencia de su saber de ello". (Introducción, p. 58); "La conciencia de un otro es ella misma autoconciencia, ser reflejado en sí, conciencia de sí misma en su ser otro". (Fuerza y entendimiento, p. 103); "la autoconciencia es la reflexión... esencialmente el retorno desde el ser otro". (Autoconciencia, p. 108); "La razón aparece como Reflexión". 
y de algunas cosas más; ${ }^{38}$ ni siquiera acerca de la verdad del mundo, del hombre o del conocimiento. Lo importante de esta formación en su carácter objetivo o positivo, no es la muerta objetividad que se representa bajo la forma del objeto, sino la actividad humana material (sensible), que está presente en ella como praxis, subjetiva, activamente..$^{39}$

No pues una formación a la que el hombre se conforma o por la que éste es conformado, y a la que como individuo se somete o pretende deba someterse; sino una formación que es conformada por el hombre, por la totalidad de los individuos humanos históricamente existentes, en cuanto se han relacionado unos con otros a la vez que se relacionan con el mundo material y en cuanto estas relaciones suyas, entre sí y respecto al mundo, son mediadas y han llegado a ser objetivadas por la reflexión.

La objetivación de tales mediaciones en objetos producidos a partir de ellas -el lenguaje, el pensamiento (o los conceptos), los valores, la cultura-, en cuanto estos objetos mediadores producidos no son en sí y por si lo verdadero, bello, bueno $\longrightarrow$ malo-, que pueda transmitirse, intercambiarse o recibirse pasándolo de mano en mano como las monedas, ${ }^{40}$ ha de disolverse, superarse, "en la praxis humana y en la comprensión de esta praxis", ${ }^{41}$ hasta perder el carácter misterioso, fascinante, -que mueve a admiración o que deslumbra con su brillo-, con que los contempla $\longrightarrow$ los arropa - la especulación.

Es necesario pues llevar nuestra atención a este proceso de superación en el que se disuelve la objetividad sin olvidar que "la disputa sobre la realidad o irrealidad de un pensamiento aislado de la práctica, es una cuestión puramente escolástica". 42

Si la filosofia que tradicionalmente enfrentara las preguntas acerca del en sí o de la verdad, ya de los conceptos acerca de la realidad, ya de la misma realidad en su totalidad, queda reducida en y a partir de Kant a mostrarnos el carácter constituido, y por lo tanto el lado activo del conocimiento

(Razón, p. 145); "el entendimiento tiene que atenerse... al ser reflejado del ser allí... en sí mismo". (Razón, p. 169); "la libertad absoluta deviene objeto de sí misma y la autoconciencia experimenta lo que esta libertad absoluta es". (Espíritu, p. 348); el alma bella "saber que se sabe a sí mismo". (Espíritu, p. 384); la verdad del espíritu "el devenir el sí mismo real, el reflejarse dentro de sí y ser sujeto". (Religión, p. 443); "el obrar es la primera separación que en sí de la simplicidad del concepto y el retorno desde esta separación". (Saber, p. 463).

${ }^{38}$ Título irónico-jocoso de un texto de Pico de la Mirandola: De omni re scibili et tractabile et de quibusdam aliis.

${ }^{39}$ C. Marx, Tesis sobre Feuerbach, tesis I.

${ }^{40}$ G.W.F. Hegel, Fenomenologia del espiritu, prólogo, ill, 1. 'Lo verdadero y lo falso', p. 27.

${ }^{41}$ C. Marx, Tesis sobre Feuerbach, tesis viii.

${ }^{42}$ C. Marx, lbid. Tesis n. 
y el uso constitutivo del entendimiento respecto de su objeto, el interés de la filosofia y en la filosofía no será en su fundamento un interés espe-culativo sino definitivamente es un interés práctico. ${ }^{43}$

La razón afirma en él su autonomía respecto a su uso práctico y restituye el justo límite de la teoría frente al impulso ciego de la imaginación en su disposición natural a trascender lo dado para ella en la experiencia: "Sabe de sí misma y sabe que ella misma es toda realidad". ${ }^{4}$

Pero saber, la razón acerca de sí misma y acerca de su obrar en abstracción de aquellas condiciones materiales de que surge y respecto de las cuales se produce - del proceso mismo por y en el que se produce no sólo su objeto, sino ella misma no sólo como para sí sino como sujeto respecto de ese objeto-, es contemplar el nulo resultado, que es lo menos importante en este desarrollo, y es afirmar, esto es, poner de nuevo frente a sí como una cosa, como un objeto no constituido sino en sí, su propio obrar, de un modo abstracto, desgarrado de sí misma y en contradicción con su existencia terrenal. ${ }^{45}$

La relativa autonomía de la razón y el reconocimiento de sus límites y de su obrar, no puede verse, pues, en abstracción del hecho de que es social e históricamente producida y de que pertenece a una forma determinada de la sociedad. ${ }^{46}$

Si la filosofía ha de ser teoría, y es de hecho Reflexión sobre la reflexión, no puede ser mera cosa de interpretación o comprensión de las teorías o las ideologías, de contemplar o criticar su fundamentación o su estructura - o la del mundo-, sino de proceder a su trans-formación en el sentido de recuperar - por la razón y por las armas de la crítica- el sentido terrenal, concreto, material y práctico, de aquella reflexión y de los productos de esa misma reflexión que aparecen, vimos, ante ella, desgarrados, extrañados, y en contradicción con su existencia real.

Por esto, en cuanto crítica, la filosofía debe transformar, con consecuencias prácticas, la relación, ya no entre la razón, o el hombre, en abstracción, y sus productos, sino entre la humanidad histórica y socialmente realizada y las formaciones en las que se encuentra enajenada o en las que le ha sido expropiado y está mediatizado el dinamismo de su vida y el valor de su trabajo, la riqueza que es producto del proceso por el que ella misma se humaniza y humaniza al mundo al apropiarse de él.

4. E. Kant, Crítica de la razón pura, "Metodología Trascendental" Sec. II, cap. I; "Del fin último del uso puro de nuestra razón" y Cfr. C. Marx Tesis sobre Feuerbach, Tesis ॥.

${ }^{44}$ G.W.F. Hegel, Fenomenologia del Espiritu. Cap. vi. "El Espíritu”. p. 259.

${ }^{45}$ C. Marx, Tesis sobre Feuerbacb, Tesis I y iv.

46 C. Marx, Ibid, Tesis viI. 
La formación filosófica, pues, en su sentido objetivo, como filosofia o filosofias históricamente existentes, de algún modo vigentes o para nosotros presentes, constituye, en su carácter inerte y como objeto o como pensamiento, vida enajenada de sí misma, producto fetichizado del trabajo y de la historia humanos, valor que adquiere una existencia y una necesidad independiente del proceso en el que se produce y que por lo tanto es expropiado al uso de su productor.

La historia de la filosofía es, en este sentido objetivo, un producto social que "cumple la función de elemento posibilitador de cierto tipo histórico de reproducción social"; ${ }^{47}$ en su positividad, como la religión, es sólo la representación del desarrollo del espíritu (vida conciente en su existencia terrenal), ${ }^{48}$ si no un cadáver, muerta objetividad, naturaleza inorgánica, recuerdo, universalidad abstracta y formalismo monótono en la forma de la irrealidad.

$\mathrm{Si}$ "la filosofía debe guardarse de pretender ser edificante", 99 la formación filosófica, como proceso formativo, activo, del sujeto, no puede detenerse en la contemplación de la riqueza, la inteligibilidad, la racionalidad o la divinidad, de tales monumentos de un pasado muerto y carente de otra forma que la forma de la irrealidad, "no se trata de purificar de lo sensible (material) al individuo y de convertirlo en sustancia pensada y pensante... sino de... la superación de los pensamientos fijos y determinados", ${ }^{50}$ - afrontar la muerte, la negatividad, hacer que los pensamientos fijos cobren fluidez - para dar paso a la seriedad de la vida pletórica que se adentra en la experiencia de la entrega a la vida de las cosas y se aproxima a la "meta en que pueda dejar de llamarse amor por el saber, para llegar a ser saber real". ${ }^{51}$

Se nos presenta así, la Reflexión sobre la reflexión, como proceso formativo, iconoclasta y desmitificadora: la historia de la filosofía no es para ella la armonía dialógica de los contrarios ni de las contradicciones en el pensamiento al margen de la historia real: es la negatividad actuante en el trabajo que hace brotar la forma del concepto, se extraña

${ }^{47}$ Bolivar Echeverria; "El concepto de fetichismo en el discurso revolucionario" en Varios Autores, La Filosofía y las Revoluciones sociales, Teoria y Praxis, No. 48; Grijalbo, México 1979; p. 90.

${ }^{48}$ Cf. G.W.F. Hegel; "Fenomenologia del espiritu" cap. ıv, B, 3; "La conciencia desventurada. Subjetivismo piadoso", p. 128. Ibid. "El yo y la apetencia", p. 113. op cit. cap. v, B, 2, a "El Placer y la Necesidad", p. 214 y podrían añadirse otras referencias en las que resalta el carácter fáustico y la afirmación de la existencia terrenal en este texto.

49 G.W.F. Hegel; Op cit. prólogo I, 2; "La formación del presente", p. 11.

${ }^{30}$ Ibid. II, 3; "La formación del Individuo" p. 24.

"I Ibid. 1, 1; "La verdad como sistema científico" p. 9. 
de su obrar y no se reconoce en él, y es, a la vez, el esfuerzo de lo negativo respecto del concepto en su objetividad fetichizada - visto como resultado, como esencia o como en sí-, al margen del proceso en el que y por el que se produce, al margen de las relaciones sociales en él representadas y al margen, o expropiado, del trabajo de su productor.

Si se pretende clarificar el sentido y destino de la historia de la filosofia en la formación filosófica, éste no puede encontrarse ligado a tenerla presente como formación filosófica, esto es, como objetividad, o producto escindido del espíritu -sujeto material e histórico que la produce-, y escindido del proceso en el que se produce - de la actividad por la que se produce--, sino que ha de considerarse en su materialidad específica, como objeto que se transforma en y por la práctica teórica, como parte efectiva de la realidad social que influye en las condiciones de reproducción o transformación de esta realidad y cuya materialidad ofrece muchas veces mayor resistencia a la transformación que otras formas de la objetividad. ${ }^{52}$

El valor o carácter formativo, pues, de la reflexión sobre esta historia, no podrá ser otro que el de permitir a los individuos históricos real y socialmente existentes recuperar su condición de sujetos $-\mathrm{y}$ no objetos-, del proceso de su producción y del producto de su actividad. La expropiación de los productos de la actividad humana, como una esencia o una forma o una cosa en sí, en abstracción o al margen de la práctica que los produce y de las relaciones sociales en que se producen, no es un problema teórico, es un problema práctico. Los misterios y fetiches que descarrían la teoría hacia el misticismo, deben encontrar su muerte, su superación y solución racional, en la práctica humana y en la comprensión de esa práctica. ${ }^{53}$

La historia de la Filosofía como instrumento o elemento de la Formación en la Filosofia, es Reflexión sobre la reflexión, y ya por serlo ha de ser crítica; pero, entregarse a la vida de las cosas o revolucionar la realidad, sólo es posible si el trabajo de lo negativo se mantiene en el esfuerzo por recuperar el carácter social, la terrenalidad, del pensamiento.

52 Carlos Pereyra, El sujeto de la bistoria. p. 77, en la Edición de Alianza Editorial. Madrid Alianza Universidad, 1984.

${ }^{53}$ C. Marx, Tesis sobre Feuerbach. Tesis vill y Cf. Tesis II y vil. 